\title{
Disclosure of the Oscillations in Kinetics of the Reactor Pressure Vessel Steel Damage At Fast Neutron Intensity Decreasing
}

Krasikov E*

National Research Centre, Kurchatov Institute 1, Kurchatov Sq., Moscow, 123182, Russia

\begin{abstract}
Fast neutron intensity influence on reactor materials radiation damage is a critically important question in the problem of the correct use of the accelerated irradiation tests data for substantiation of the materials workability in real irradiation conditions that is low neutron intensity. Investigations of the fast neutron intensity (flux) influence on radiation damage and experimental data scattering reveal the existence of non-monotonous sections in kinetics of the reactor pressure vessels (RPV) steel damage. Discovery of the oscillations as indicator of the self -organization processes presence give reasons for new ways searching on reactor pressure vessel (RPV) steel radiation stability increasing and attempt of the self-restoring metal elaboration. Revealing of the wavelike process in the form of non monotonous parts of the kinetics of radiation embrittlement testifies that periodic transformation of the structure take place. This fact actualizes the problem of more precise definition of the RPV materials radiation embrittlement mechanisms and gives reasons for search of the ways to manage the radiation stability (Nano structuring and so on to stimulate the radiation defects annihilation), development of the means for creating of more stableness selfrecovering smart materials.
\end{abstract}

\section{Keywords: Oscillations; Reactor pressure; Radiation}

\section{Introduction}

Modern nuclear power plants based on PWR type reactors. As the main safety barrier RPV have to be capable to working at any operating regimes including in an emergency.

Radiation stability is a dominating factor of the RPV life cycle. In turn substantiation of the normative dependencies of the RPV materials radiation embrittlement was carried out in research reactors at neutron fluxes that were two and more orders higher than at RPV operation. Surveillance specimens (SS) programmes are more adequate for RPV embrittlement control but at this case lead factor may be also high (up to 20). So, scale of the flux effect influence touch upon hypersensitive questions of the RPV real radiation embrittlement. This context became the main motivation of the present work carrying-out and publication.

Operating RPVs are subject to multi-factor influence. It is practically impossible to reproduce some of this factors («long-time bias», e.g.) in the framework of experimental investigations including RPV surveillance specimens tests. Detailed information that can be obtained by means of taking through RPV wall samples immediate from the decommissioned RPVs is more representative than received by any another ways and therefore has a highest value.

\section{Experimental Procedures and Test Results}

Along with routine investigations in Russia systematic research on actual radiation embrittlement of the decommissioned pressure vessels via through samples (trepans) has been carried out.

The earliest commercial PWR prototype unit Novovoronezh-1 (210 MWe) RPV after 20 years (1964-1984) of operation was trepanned in 1987. Then Novovoronezh-2 (365 MWe, 1969-1990), the oldest PWR type experimental prototype reactor EPR (1956-1986) and, finely, nuclear icebreaker «Lenin»" RPVs also were trepanned.

Through-thickness RPV wall samples had been cut out using trepanning tools such as boring machine with annular drill, anodicmechanical and electric resistance cut machines. Typical dimensions of trepans were 120-140 mm in diameter and 120-140 mm lengthwise.
Test pieces and specimens were fabricated by means of electrodischarge wire cutting machine.

The general dependence of the Transition Temperature Shift (TTS) on radiation embrittlement coefficient (REC) $A_{F}$ is as follows:

$\mathrm{TTS}=\mathrm{A}_{\mathrm{F}} \times \mathrm{F}(1)$,

Where, $A_{F}$ is the radiation embrittlement coefficient (REC chemical factor) and $\mathrm{F}$ is the fast $(\mathrm{E}>0,5 \mathrm{MeV})$ neutron fluence in units of $10^{18} \mathrm{~cm}^{-2}$ (fluence factor), $\mathrm{n}$ - coefficient $(\sim 1 / 3)$.

For Russian RPV Cr-Mo-V base steel

$\mathrm{A}_{\mathrm{F}}=\mathrm{A} \times(\mathrm{P}+0,07 \mathrm{Cu})(2)$,

Where, $A_{F}$ - coefficient $\left(800\right.$ at $\left.270^{\circ} \mathrm{C}\right), \mathrm{P}$ and $\mathrm{Cu}$ - are the mass concentrations of these elements.

One of the Novovoronezh-1 RPV trepans for parallel study was delivered to IVO (Finland). Team-work obtained serrated results force to lose in thoughts (Figure 1). No less unexpected became the results of a special research of the SS Kolskaya-3 NPP [1] that confirm the subsistence of the flux effect at the initial section of the neutron exposition as well as data on post irradiation tests of the trepans cut out of nuclear icebreaker "Lenin" RPV [2].

Particular curiosity to provoke paradox results of the SS zero embrittlement obtained in Russia (Figure 2) [3] and abroad (Figure 3) [4-7] Stress of incomprehension diminished when finding analogous data on non monotonous SS degradation with commentary "quite atypical" [4].

*Corresponding author: Krasikov E, Laboratory Head, National Research Centre, Kurchatov Institute 1, Kurchatov Sq., Moscow, 123182, Russia, Tel: +7 499 - 1969233; E-mail: ekrasikov@mail.ru

Received June 21, 2016; Accepted July 26, 2016; Published August 03, 2016

Citation: Krasikov E (2016) Disclosure of the Oscillations in Kinetics of the Reactor Pressure Vessel Steel Damage At Fast Neutron Intensity Decreasing. J Appl Mech Eng 5: 226. doi: 10.4172/2168-9873.1000226

Copyright: (c) 2016 Krasikov E, et al. This is an open-access article distributed under the terms of the Creative Commons Attribution License, which permits unrestricted use, distribution, and reproduction in any medium, provided the original author and source are credited. 
Citation: Krasikov E (2016) Disclosure of the Oscillations in Kinetics of the Reactor Pressure Vessel Steel Damage At Fast Neutron Intensity Decreasing. J Appl Mech Eng 5: 226. doi: 10.4172/2168-9873.1000226

In addition to this circumstances attention is drawn to the fact that the considerable scatter of the experimental data take place. Figure 3 presents data scattering for SS of the Spanish nuclear power plants.

One can note unexpected low embrittlement at the region of high fluence and zero embrittlement at the neutron fluence area of $2 \times 10^{19} \mathrm{~cm}^{-2}$.

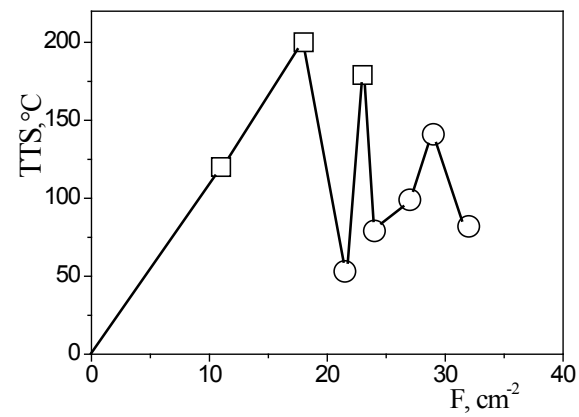

Figure 1: Dependence of the Novovoronezh-1 RPV weld metal TTS on the fast neutron fluence ( $\square-\mathrm{NRC}$ "Kurchatov Institute", ○- IVO Finland).

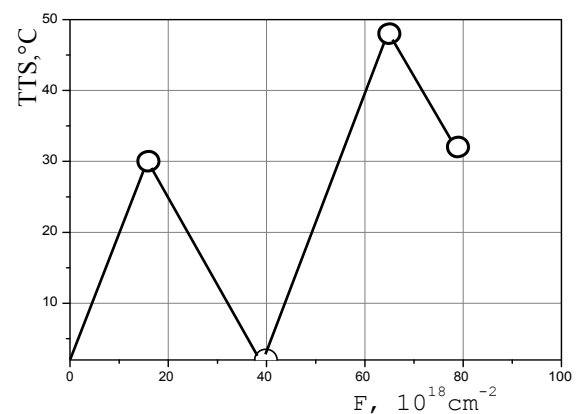

Figure 2: Dependence of the Rovno-1 RPV base metal TTS on the fast neutronfluence. Neutron flux $6 \times 10^{10} \mathrm{~cm}^{-2} \mathrm{c}^{-1}$ (specimens from upper containers).

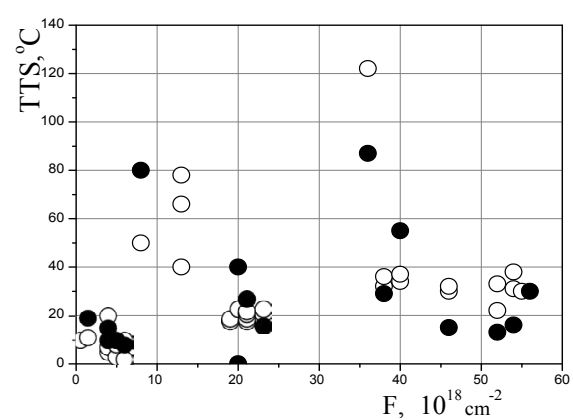

Figure 3: Dependence of the TTS on the fast neutron fluence from surveillance data for Spanish nuclear power plants base metal $(\circ)$ and welds $(\bullet)$.

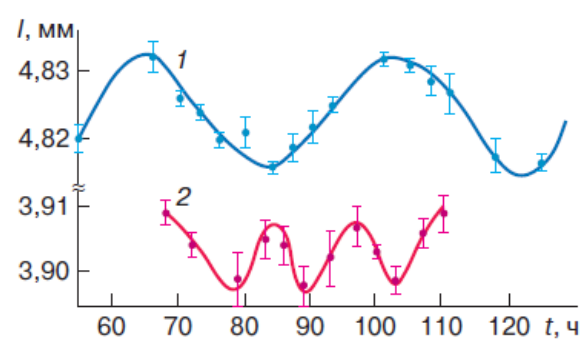

Figure 4: Change in length ( $\mathrm{mm}$ of the plutonium specimens with different content of ${ }^{238} \mathrm{Pu}$ isotope against time (hours): $1-7.3 \%{ }^{238} \mathrm{Pu}, 2-80 \%{ }^{238} \mathrm{Pu}$.

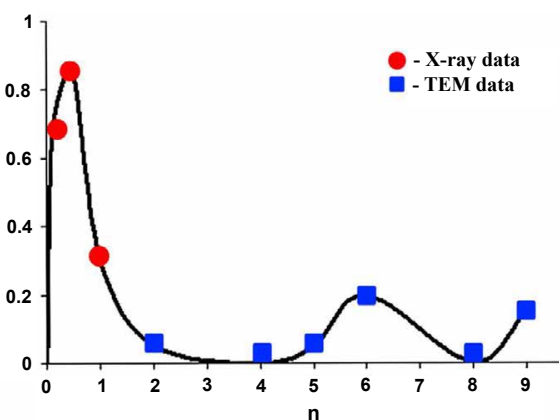

Figure 5: Volume fraction of crystalline phase $\mathrm{V}$ as a function of the number of the mobile anvil rotations $\mathrm{n}$ for the amorphous Ti50Ni25Cu25 alloy.

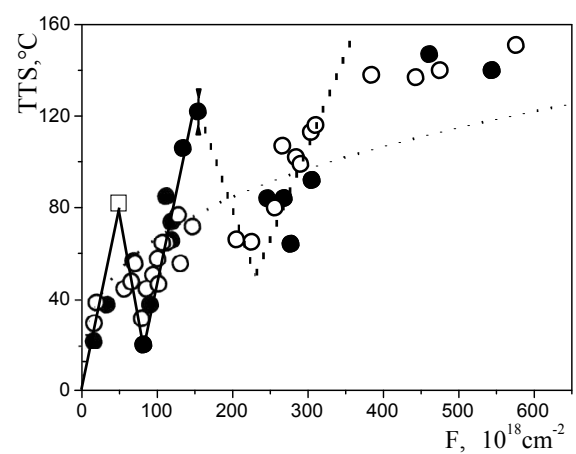

Figure 6: Dependence of the transition temperature shift against neutron fluence from surveillance data for WWER-440/213 base metal and welds. O flux $\sim 30 \times 10^{11} \mathrm{~cm}^{-2} \mathrm{c}^{-1}, \bullet-$ flux $\sim 4 \times 10^{11} \mathrm{~cm}^{-2} \mathrm{c}^{-1}, \square-$ flux $\sim 1.3 \times 10^{11} \mathrm{~cm}^{-2} \mathrm{c}^{-1}$.

\section{Data Analysis and Discussion}

Revealed non monotony has to be inspired by the peculiarity of the copper impurities containing metal degradation process at low flux when after forced embrittlement at the initial stage mitigation follows [8]. At the same time refinement of the steel up to threshold level of $0,05 \% \mathrm{Cu}$ that slows down flux effect changes the scatter slightly, SS data scatter exceeds this parameter for data obtained in test reactors (high flux) [9]. One can assume, that factor exists which generate oscillating process in mechanism of embrittlement and become more apparent with neutron flux lowering. Conversely, at high level of the flux it is hardly noticeable because amplitude of a oscillation decrease while frequency increase. As an analogue of temporal self-organization in solids under irradiation one can cite professor V.S. Chmelevskaya data on periodic change in length of the plutonium specimens with different content of ${ }^{238} \mathrm{Pu}$ isotope (Figure 4) [10].

Hypothetically we assume the presence of the oscillation component in kinetics of the neutron embrittlement process that arise from radiation defects periodic beginning and annealing, which in its turn is a result of the metal structure temporal self-organization, similar to indicate in (Figure 2) effect we find out the mention concerning structural and phase transitions in the amorphous and nanocrystalline $\mathrm{Ti}_{50} \mathrm{Ni}_{25} \mathrm{Cu}_{25}$ alloy upon high-pressure torsion [11]. Figure 5 demonstrates volume fraction of crystalline phase $\mathrm{V}$ as a function of the number of the mobile anvil rotations $\mathrm{n}$ for the amorphous $\mathrm{Ti}_{50} \mathrm{Ni}_{25} \mathrm{Cu}_{25}$ alloy.

Assumed periodicity of the embrittlement confirms the analysis of the dependence of the transition temperature shift against neutron fluence from surveillance data for WWER-440/213 base metal and welds (Figure 6). 
Citation: Krasikov E (2016) Disclosure of the Oscillations in Kinetics of the Reactor Pressure Vessel Steel Damage At Fast Neutron Intensity Decreasing. J Appl Mech Eng 5: 226. doi: 10.4172/2168-9873.1000226

Page 3 of 3

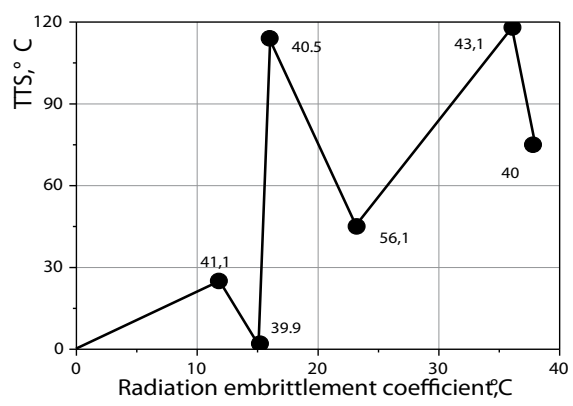

Figure 7: Dependence of the transition temperature shift against radiation embrittlement coefficient (chemical factor) $A_{F}$ from surveillance data for WWER$440 / 213$ base metal and welds.

Possibly linear approximation is simplification, but one can notice the serrated character of the dependence and high amplitude of the oscillations at the initial stage of neutron exposition. In addition an attempt was undertake to consider the dependence of the transition temperature shift against radiation embrittlement coefficient (chemical factor) $A_{F}$ from surveillance data for WWER-440/213 weld and base metal (Figure 7). In this case initial data were used for neutron fluences at the range of $(40 \div 60) \times 10^{18} \mathrm{~cm}^{-2}$. Again oscillating process become apparent. It is necessary note that data for different intensities and materials (weld and base metals) were used. It seems that oscillation factor may advance to the forefront.

\section{Conclusion}

Disclosure of the oscillations - sign of the self-organization - in kinetics of the reactor pressure vessels (RPV) steel damage at fast neutron intensity decreasing testifies the periodic transformations of the metal structure and underlines the actuality of the thorough knowledge radiation damage mechanisms deepening.

As a hypothesis we suppose that at some stages of irradiation damaged metal have to be partially restored by irradiation i.e., neutron bombardment. Nascent during irradiation structure undergo occurring once or periodically transformation in a direction both degradation and recovery of the initial properties. According to our hypothesis at some stage(s) of metal structure degradation neutron bombardment became recovering factor. As a result oscillation arise that in tern lead to enhanced data scatter.

So, one can assume, that factor exists which generate oscillating process in mechanism of embrittlement and become more apparent with neutron flux lowering. Conversely, at high level of the flux it is hardly noticeable because amplitude of a oscillation decrease while frequency increase. Hypothetically we assume the presence of the oscillation component in kinetics of the neutron embrittlement process that arise from radiation defects periodic beginning and annealing, which in its turn is a result of the metal structure temporal selforganization.

Revealing of the wavelike process in the form of non monotonous parts of the kinetics of radiation embrittlement process - sign of selforganization, that testify to periodic transformation of the structure actualize the problem of more precise definition of the RPV materials radiation embrittlement mechanisms and give reasons for search of the ways to manage the radiation stability (nanostructuring [12] and so on to stimulate the radiation defects annihilation), development of the means for creating of more stableness self recovering smart materials.

\section{Refrences}

1. Nikolaenko V, Krasikov E (2004) Neutron flux influence on the WWER-440/213 reactor pressure vessel materials embrittlement. Atomic energy 97: 177-182.

2. Krasikov E, Nikolaenko V (2008) Neutron flux influence on the WWER-440/213 reactor pressure vessel materials embrittlement. Atomic energy 105: 201-205.

3. Gerard R, Fabry A (1996) In-service embrittlement of the pressure vessel welds at the Doel I and II NPPs in D Gelles R Nanstad (eds.) Effects of radiation on materials ASTM STP West Conshohocken PAAnn Arbor.

4. Krasikov E, Nikolaenko V (2015) Non-monotonic embrittlement of vessel steel. Atomic energy 119: 46-50.

5. Debarberis L, Ballesteros A (2004) Radiation embrittlement of Spanish NPP base metals and welds; mechanistic interpretation of available surveillance data. IAEA specialists meeting on irradiation effects and mitigation in reactor pressure vessels and internals. Gus Khrustalny.

6. William L, Server M (2004) Assessment of US embrittlement correlation equations considering the latest available surveillance data. IAEA specialists meeting on irradiation effects and mitigation in reactor pressure vessels and internals Gus Khrustalny.

7. Williams $T$ (2013) Knowledge gaps in toughness and irradiation: lessons of the past, prospects for the Future. IAEA Technical Meeting Vienna.

8. Krasikov E, Nikolaenko V (2016) Radiation annealing of radiation embrittlement of the reactor pressure vessel steel. IOP Publishing IOP Conference Series, Materials Science and Engineering.

9. (2002) Review of dose rate effects on RPV embrittlement: Joint EPRI-CRIEP RPV: Embrittlement Studies (1999-2004) EPRI Palo Alto CA 1003529 and CRIEPI Tokyo, Japan.

10. Chmelevskaya V (2000) Processes of self-organization in solids. Soros educational journal 6: 85-91.

11. Sundeev R, Glezer A, Shalimova A (2014) Structural and phase transitions in the amorphous and nanocrystalline $\mathrm{Ti}_{50} \mathrm{Ni}_{25} \mathrm{Cu}_{25}$ alloy upon high-pressure torsion. Materials Letters 133: 32-34.

12. Bai X, Voter A, Hoagland R, Nastasi M (2010) Efficient annealing of radiation damage near grain boundaries via interstitial emission. Science 327: 1631-1634 